\title{
Clip on Staple Method to Prevent Bile Leakage in Anatomical Liver Resection Using Stapling Devices
}

\author{
MIZUKI NINOMIYA, TAKAHIRO TOMINO, RUMI MATONO and TAKASHI NISHIZAKI \\ Department of Surgery, Matsuyama Red Cross Hospital, Ehime, Japan
}

\begin{abstract}
Background/Aim: Bile leakage after liver surgery is still a problem to be solved. Here, we introduce a simple new technique, the Clip on Staple method, a preventive measure for bile leakage after anatomical liver resection using a stapling device. Patients and Methods: Before liver parenchymal transection, the roots of Glissonean pedicles for target segments were dissected and divided using the Endo-GIA ${ }^{T M}$ Tri-Staple ${ }^{T M}$ Curved Tip. After the parenchymal transection was completed, the full length of the stapled stump was reinforced by multiple clips. The DS Titanium Ligation Clip was used as the clipping device. Results: Twenty patients underwent this technique during anatomical liver resections with stapling devices. No patient developed postoperative bile leakage of any grade. There was no reoperation or readmission within 90 days. Conclusion: The Clip on Staple method is simple and offers a preventive effect for postoperative bile leakage after anatomical liver resection using stapling devices.
\end{abstract}

Despite significant technical advancements in the field of liver surgery, bile leakage remains a significant postoperative morbidity $(1,2)$. Bile leakage is associated with subsequent severe complications such as intra-abdominal abscess, peritonitis, and sepsis. With the recent trend toward minimally invasive laparoscopic surgery, stapling devices have been introduced as a measure for division of the Glissonean pedicles or the hepatic veins (3-5). Although stapling device offers a simple and uniform quality of closure for every surgeon, it also carries the risk of malfunction (6-8). Actually, bile leakage from the staple line is occasionally encountered $(4,9)$. In the case of anatomical liver resection, most of the leakage points are observed

Correspondence to: Mizuki Ninomiya, MD, Ph.D., Department of Surgery, Matsuyama Red Cross Hospital, Ehime 790-8524, Japan. Tel: +81 899241111, Fax: +81 899226892, e-mail: ninom@surg2.med.kyushu-u.ac.jp

Key Words: Bile leakage, complication, liver surgery. around the hilar Glissonean stump and not at the peripheral parenchymal cutting plane, because parenchymal resection is usually performed along the intersegmental plane.

We presumed that some bile leakage after anatomical liver resection using stapling devices was attributable to stapler malfunction and the subsequent delayed loosening of the stapled stump. Based on this hypothesis, we devised a new, simple technique, the Clip on Staple method, a preventive measure for postoperative bile leakage after anatomical liver resection using stapling devices. In this report, we present our initial results of 20 patients who underwent our new technique in anatomical liver resection using stapling devices.

\section{Patients and Methods}

Patients. Among 85 patients who underwent liver resection at our institution between July 2017 and October 2019, 20 patients had undergone our new technique-Clip on Staple method, a preventive measure for bile leakage in anatomical liver resection using stapling devices. Written informed consent was obtained from all patients preoperatively. The study protocol was approved by the Institutional Review Board in our hospital (No.: 789).

Clip on Staple method. Anatomical liver resection was performed basically with the extrahepatic Glissonean pedicle approach (10, 11). Briefly, the roots of the Glissonean pedicles for the target segments were dissected from the liver hilum and encircled before the liver parenchymal transection. After temporal occlusion of these pedicles and confirmation of the demarcation line of the corresponding segments, the Glissonean pedicles were transected using the Endo-GIA ${ }^{\mathrm{TM}}$ Tri-Staple ${ }^{\mathrm{TM}}$ Curved Tip, $45 \mathrm{~mm}$, camel (Medtronic, Minneapolis, MN, USA), followed by the liver parenchymal transection using the CUSA along the demarcation line and the respective landmarks. In the left hemi-hepatectomy, the Glissonean pedicle of the left lobe was transected above the Arantius plate. In the right hemi-hepatectomy, the Glissonean pedicles of the anterior and posterior segments were separately isolated and transected. After the parenchymal transection was completed, the full length of the stapled stump was reinforced by multiple clips (Figure 1). As a clipping device, the DS Titanium Ligation Clip, SM size, without latch (B. Braun, Aesculap ${ }^{\circledR}$, Tuttlingen, Germany) was used. 


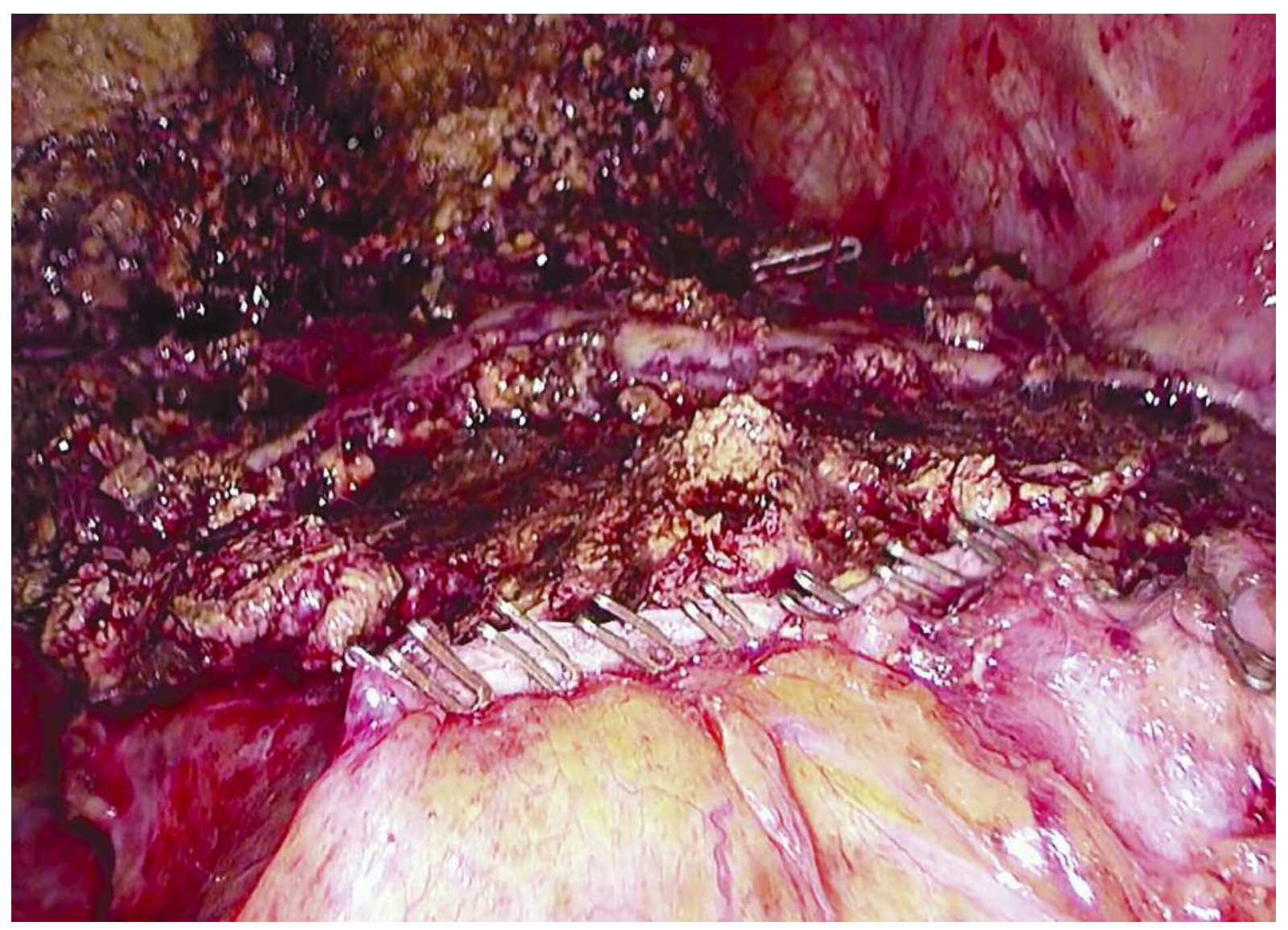

Figure 1. The Clip on Staple method in patient with left hemi-hepatectomy. After dividing the left Glissonean pedicle with the Endo-GIA ${ }^{T M}$ TriStaple $^{T M}$, multiple DS Titanium Clips were applied on the full length of the staple line.

Perioperative management. At least one 19 Fr. J-Vac silicon drain was placed near the liver parenchymal plane. The bilirubin level of the drainage fluid was measured until the drain was removed. The drain was removed until postoperative day 5 if the drainage fluid was clear and bile leakage and bacterial contamination were absent. All patients were followed for 3 months postoperatively.

Bile leakage. The primary outcome was postoperative bile leakage, defined according to the International Study Group of Liver Surgery (ISGLS) definitions (12). In summary, bile leakage is clinically defined as drain bilirubin levels at least 3 times greater than the serum bilirubin levels measured at the same time on postoperative day 3 or later, or as the need for radiologic intervention or relaparotomy. Grade A leakage requires little or no change in the patients' clinical management. Grade B leakage requires therapeutic intervention such as endobiliary decompression and/or percutaneous drainage of the biloma, or a Grade A leakage lasting for more than 7 days. Grade $\mathrm{C}$ leakage requires management with reoperation.

\section{Results}

Patient characteristics, summaries of the surgical procedures, and the patients' post-operative course are shown in Table I. In 19 of the 20 patients who had undergone the Clip on
Staple method, surgeries were performed laparoscopically. Surgical procedures included 13 hemi-hepatectomies, 4 sectionectomies, and 3 segmentectomies. No patient developed postoperative bile leakage of any grade. There was no reoperation or readmission within 90 days.

\section{Discussion}

Although the exact post-hepatectomy bile leakage site is not clear, bile leakage reportedly occurs in $3-12 \%$ (13). In the clinical setting, bile leakage from the stapled Glissonean stump is occasionally encountered (Figure 2). In contrast to leakage from peripheral liver parenchyma in limited resection, bile leakage from the hilar Glissonean pedicles in anatomical resection tends to be refractory. This is due to the leakage point being in the hilar and the relatively large bile duct. This condition usually necessitates invasive intervention, i.e., endoscopic naso-biliary drainage for biliary decompression or percutaneous drainage (14). Therefore, it is important to implement effective preventive measures to lessen the incidence of bile leakage. 


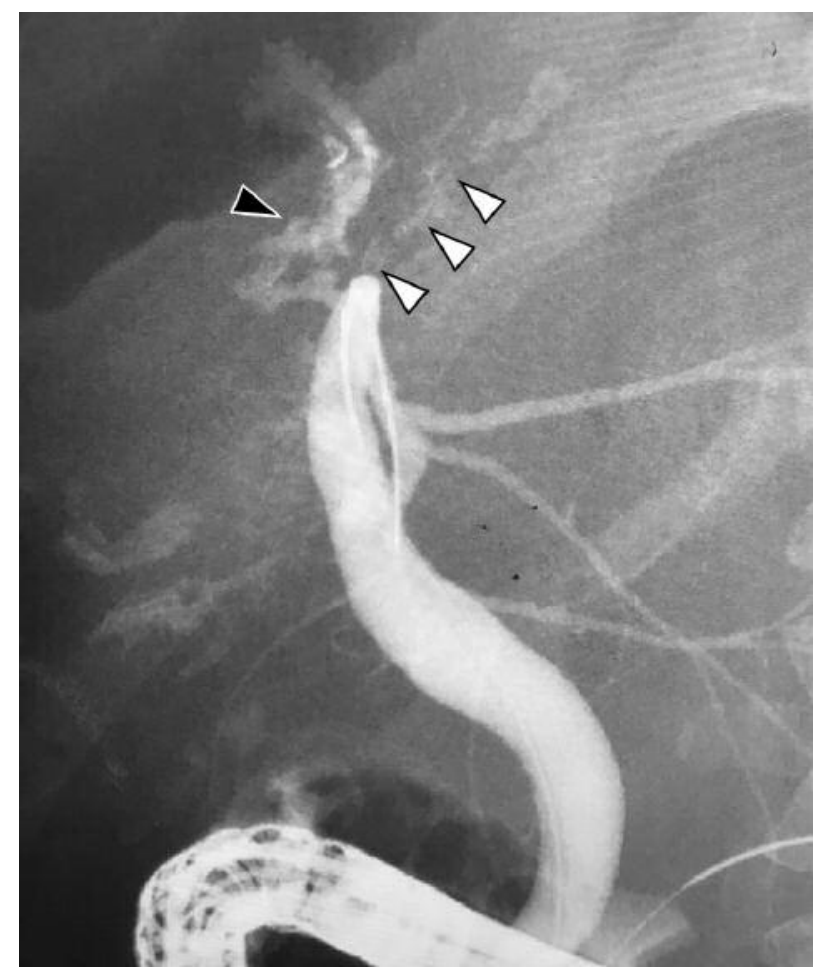

Figure 2. Representative image of postoperative bile leakage from the stapled stump. A case of postoperative bile leakage occurred in a patient who underwent right hemi-hepatectomy using a stapling device without the Clip on Staple method. Endoscopic retrograde cholangiography revealed a leakage of the contrast media (black arrowhead) from the stapled stump (white arrowheads).

The exact pathogenesis of bile leakage after stapling division of the Glissonean pedicles is unknown. However, postoperative bile leakage occurs occasionally despite a negative intraoperative bile leakage test. This fact suggests that the stapled stump might loosen with time and the expanding force of the compressed Glissonean structure overwhelms the holding power of the staples (8). Figure 3 shows representative images that suggest the possibility of a delayed loosening of the stapled stump. Compared to the image just after division of the left Glissonean pedicle by the stapling device (Figure 3a), the image of the same patient 2 hours later showed an apparent widening of the stapled stump (Figure 3b). The Clip on Staple method is anticipated to prevent stump widening following improper staple formation and subsequent postoperative bile leakage.

A suture reinforcement of the stapled stump is another available method that is used as a preventive measure for bile leakage after stapler division. However, in an era of minimally invasive surgery, laparoscopic liver surgery has been increasingly performed globally (2). The most
Table I. Patient characteristics, summaries of the surgical procedures, and outcomes.

\begin{tabular}{|c|c|}
\hline Age median (range) & $75(46-84)$ \\
\hline Gender (male/female) & $17 / 3$ \\
\hline \multicolumn{2}{|l|}{ Diseases } \\
\hline Hepatocellular carcinoma & $10(50 \%)$ \\
\hline Intrahepatic cholangiocarcinoma & $4(20 \%)$ \\
\hline Metastatic tumor & $5(25 \%)$ \\
\hline Others & $1(5 \%)$ \\
\hline \multicolumn{2}{|l|}{ Surgical approach } \\
\hline Open & 1 \\
\hline Laparoscopic & 19 \\
\hline \multicolumn{2}{|l|}{ Surgical Procedure } \\
\hline Left hemi-hepatectomy & 7 \\
\hline Right hemi-hepatectomy & 6 \\
\hline Anterior sectionectomy & 1 \\
\hline Medial sectionectomy & 1 \\
\hline Lateral sectionectomy & 2 \\
\hline Segmentectomy & $3(\mathrm{~S} 2 / \mathrm{S} 2 / \mathrm{S} 8)$ \\
\hline \multicolumn{2}{|l|}{ Postoperative complication } \\
\hline Bile leakage (Grade A/B/C) & $0 / 0 / 0$ \\
\hline Cholangitis & 1 \\
\hline Surgical site infection & 1 \\
\hline Pulmonary embolism (asymptomatic) & 1 \\
\hline Refractory ascites & 1 \\
\hline Postoperative hospital stay (days) median (range) & $10(7-21)$ \\
\hline Re-operation within 90 days & 0 \\
\hline Re-admission within 90 days & 0 \\
\hline
\end{tabular}

prominent feature of the Clip on Staple method is its simplicity and ease of application, even in laparoscopic surgeries. Only a few minutes is required to apply multiple clips on the stapled stump.

Although a prospective study is necessary to confirm the benefits of our technique, we believe that the Clip on Staple method is simple and offers a preventive effect for postoperative bile leakage after anatomical liver resection using stapling devices.

\section{Conflicts of Interest}

The Authors declare no conflicts of interest regarding this study.

\section{Authors' Contributions}

Guarantors of integrity of the entire study, M.N., T.N.; Study concepts, M.N.; Study design, M.N., T.N.; Patient management, T.T., R.M.; Data acquisition, M.N., T.T., R.M.; Data analysis, M.N., T.N.; Manuscript editing, M.N., T.T., R.M.; Manuscript review, T.N.

\section{Acknowledgements}

This research did not receive any specific grant from funding agencies in the public, commercial, or not-for-profit sectors. 

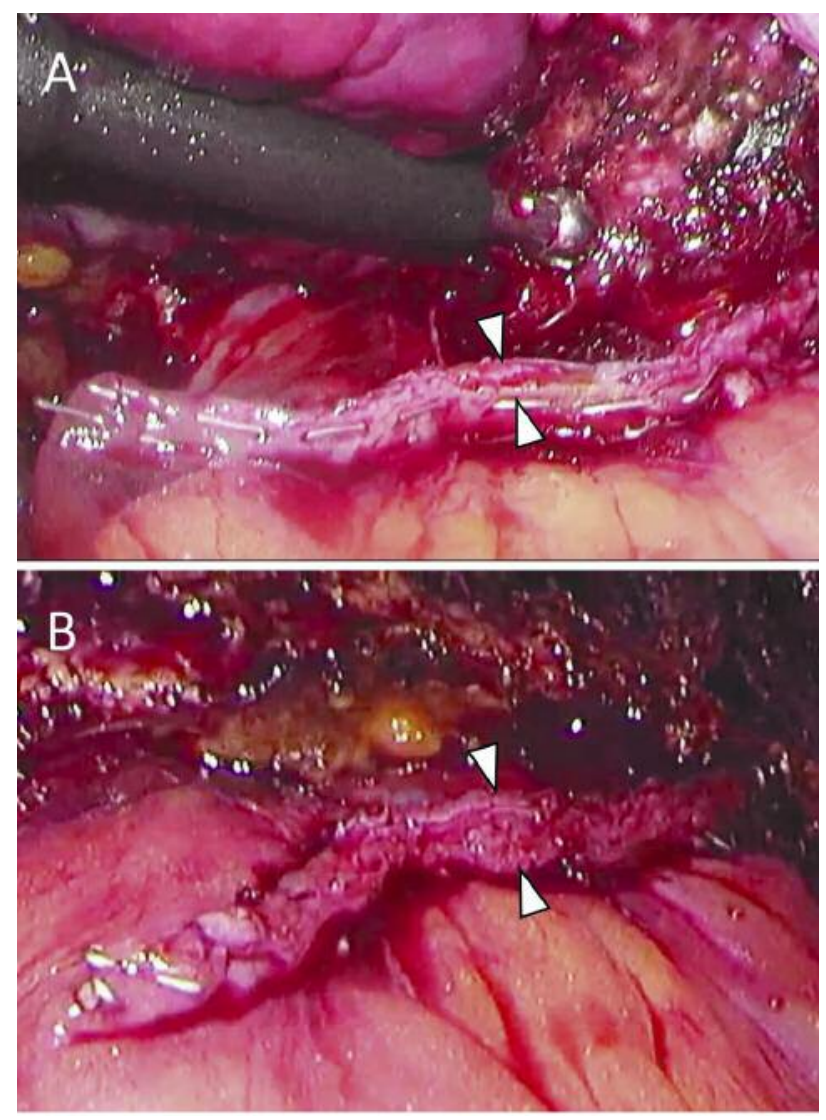

Figure 3. Representative images of delayed loosening of the stapled stump. (A) Image taken just after division of the left Glissonean pedicle by a stapling device in the case of left hemi-hepatectomy. (B) Image of the same patient taken 2 hours later. Width of the stapled stump appears widened (white arrowheads).

\section{References}

1 Martin AN, Narayanan S, Turrentine FE, Bauer TW, Adams RB, Stukenborg GJ and Zaydfudim VM: Clinical factors and postoperative impact of bile leak after liver resection. J Gastrointest Surg 22: 661-667, 2018. PMID: 29247421. DOI: 10.1007/s11605-017-3650-4

2 Morise Z: Developments and perspectives of laparoscopic liver resection in the treatment of hepatocellular carcinoma. Surg Today 49: 649-655, 2019. PMID: 30649611. DOI: 10.1007/ s00595-019-1765-9

3 Honda G, Kurata M, Okuda Y, Kobayashi S, Tadano S, Yamaguchi T, Matsumoto H, Nakano D and Takahashi K: Totally laparoscopic hepatectomy exposing the major vessels. J Hepatobiliary Pancreat Sci 20: 435-440, 2013. PMID: 23269462. DOI: $10.1007 / \mathrm{s} 00534-012-0586-7$

4 Hasegawa Y, Nitta H, Takahara T, Katagiri H, Kanno S and Sasaki A: Pure laparoscopic living donor hepatectomy using the Glissonean pedicle approach (with video). Surg Endosc 33: 2704-2709, 2019. PMID: 31087174. DOI: 10.1007/s00464-01906818-7
5 Yao DB and Wu SD: Application of stapling devices in liver surgery: Current status and future prospects. World J Gastroenterol 22: 7091-7098, 2016. PMID: 27610019. DOI: 10.3748/wjg.v22.i31.7091

6 Chekan E and Whelan RL: Surgical stapling device-tissue interactions: What surgeons need to know to improve patient outcomes. Med Devices Evid Res 7: 305-318, 2014. PMID: 25246812. DOI: 10.2147/MDER.S67338

7 Deng DY, Meng MV, Nguyen HT, Bellman GC and Stoller ML: Laparoscopic linear cutting stapler failure. Urology 60: 415-420, 2002. PMID: 12350475. DOI: 10.1016/s0090-4295(02)01778-8

8 Ninomiya M, Tomino T, Matono R, Motomura T, Hideaki U and Nishizaki T: Clip on Staple method reduces clinically relevant pancreatic fistula after distal pancreatectomy. Anticancer Res 39: 6799-6806, 2019. DOI: 10.21873/anticanres.13895

9 Maeda K, Honda G, Kurata M, Homma Y, Doi M, Yamamoto J and Ome Y: Pure laparoscopic right hemihepatectomy using the caudodorsal side approach (with videos). J Hepatobiliary Pancreat Sci 25: 335-341, 2018. PMID: 29770584. DOI: 10.1002/jhbp.563

10 Sugioka A, Kato Y and Tanahashi Y: Systematic extrahepatic Glissonean pedicle isolation for anatomical liver resection based on Laennec's capsule: proposal of a novel comprehensive surgical anatomy of the liver. J Hepatobiliary Pancreat Sci 24: 17-23, 2017. PMID: 28156078. DOI: 10.1002/jhbp.410

11 Cho A, Yamamoto H, Kainuma O, Ota T, Park S, Yanagibashi H, Arimitsu H, Ikeda A, Souda H, Nabeya Y, Takiguchi N and Nagata M: Arantius' ligament approach for the left extrahepatic Glissonean pedicle in pure laparoscopic left hemihepatectomy. Asian J Endosc Surg 5: 187-190, 2012. PMID: 23095298. DOI: 10.1111/j.1758-5910.2012.00139.x

12 Koch M, Garden OJ, Padbury R, Rahbari NN, Adam R, Capussotti L, Fan ST, Yokoyama Y, Crawford M, Makuuchi M, Christophi C, Banting S, Brooke-Smith M, Usatoff V, Nagino M, Maddern G, Hugh TJ, Vauthey JN, Greig P, Rees M, Nimura Y, Figueras J, Dematteo RP, Büchler MW and Weitz J: Bile leakage after hepatobiliary and pancreatic surgery: A definition and grading of severity by the International Study Group of Liver Surgery. Surgery 149: 680-688, 2011. PMID: 21316725. DOI: $10.1016 /$ j.surg.2010.12.002

13 Brooke-Smith M, Figueras J, Ullah S, Rees M, Vauthey JN, Hugh TJ, Garden OJ, Fan ST, Crawford M, Makuuchi M, Yokoyama Y, Büchler M, Weitz J and Padbury R: Prospective evaluation of the International Study Group for Liver Surgery definition of bile leak after a liver resection and the role of routine operative drainage: An international multicentre study. Hpb 17: 46-51, 2015. PMID: 25059275. DOI: $10.1111 / \mathrm{hpb} .12322$

14 Terajima H, Ikai I, Hatano E, Uesugi T, Yamamoto Y, Shimahara $\mathrm{Y}$ and Yamaoka Y: Effectiveness of endoscopic nasobiliary drainage for postoperative bile leakage after hepatic resection. World J Surg 28(8): 782-786, 2004. PMID: 15457358. DOI: $10.1007 / \mathrm{s} 00268-004-7385-5$ 